\title{
O PROCESSO DE ANÁLISE DO AMBIENTE E SUA RELAÇÃO COM A APRENDIZAGEM ORGANIZACIONAL: UM ESTUDO DE CASO
}

\author{
Adilson Caldeira \\ adilson.caldeira@mackenzie.br \\ Universidade Presbiteriana Mackenzie - São Paulo, SP/Brasil \\ Arilda Schmidt Godoy \\ arilda-godoy@uol.com.br \\ Universidade Presbiteriana Mackenzie - São Paulo, SP/Brasil
}

Recebido em 14/09/2010

Aprovado em 15/06/2012

Disponibilizado em 01/12/2012

Avaliado pelo sistema double blind review

Revista Eletrônica de Administração

Editor: Luís Felipe Nascimento

ISSN 1413-2311 (versão on-line)

Editada pela Escola de Administração da Universidade Federal do Rio Grande do Sul.

Periodicidade: Quadrimestral

Sistema requerido: Adobe Acrobat Reader.

\section{RESUMO}

Este estudo foi realizado a partir da questão: "Quais as contribuições do processo de análise do ambiente para a aprendizagem organizacional?" Em busca da resposta, efetuou-se, a princípio, uma revisão da literatura que aborda os conceitos e principais aplicações relativos às formas pelas quais a aprendizagem se processa nas organizações. Na seqüência procurou-se igualmente contextualizar a fundamentação teórico-conceitual que permeia os estudos atinentes à estratégia empresarial na atualidade. No plano empírico, realizou-se uma pesquisa qualitativa por meio de estudo de caso na empresa Petrobras, na qual os dados foram colhidos utilizando-se entrevistas. Em primeiro lugar, são apresentados os dados históricos e a descrição do processo de análise do ambiente efetuada no processo de planejamento estratégico na organização pesquisada. A seguir, apresenta-se a visão dos gestores a respeito do aprendizado decorrente desse processo. As declarações dos executivos foram classificadas por categorias e submetidas a análise de conteúdo. Os resultados revelam que os entrevistados vêem a análise do ambiente como meio de aprendizagem organizacional e demonstram acreditar que a aprendizagem resultante contribui para o desempenho da empresa por desenvolver sua capacitação para aprimorar suas ações administrativas. Assim sendo, o estudo proporciona a visão de uma associação entre os processos de planejamento estratégico e aprendizagem nas organizações.

Palavras-Chave: Análise do Ambiente; Aprendizagem Organizacional; Estratégia; Planejamento Estratégico.

REAd I Porto Alegre - Edição 73 - Nº 3 - set/dez 2012 - p. $779-812$ 
O processo de análise do ambiente e sua relação com a aprendizagem organizacional: um estudo de caso

\title{
THE PROCESS OF ENVIRONMENT ANALYSIS AND ITS RELATIONSHIP TO ORGANIZATIONAL LEARNING: A CASE STUDY
}

\begin{abstract}
This study considered the question: "Which are the contributions of environment analysis to organizational learning?" It principiates by means of a literature review that discusses the key concepts and applications related to ways in which learning occurs in organizations. Subsequently, a brief frame concerning to business strategy contextualizes the theoretical and conceptual studies that permeates the discussion of this matter presently. Empirically, a qualitative research was conducted by means of a single case study approach conducted at Petrobras, using interviews. After presenting the history of company and its strategic planning process, the study discusses how managers see their learning when analysing environment. The research reveals that managers see environment analysis as a way to provide learning. They also believe that outcoming learning contributes to company's performance by improving its management ability. The study provided a first look at the nature and composition of both phenomena - Learning and Strategy - in the context of an organization.
\end{abstract}

Keywords: Environment Analysis; Organizational Learning; Strategy; Strategic Planning.

\section{EL PROCESO DE ANÁLISIS DEL MEDIO AMBIENTE Y SU RELACIÓN CON LA APRENDIZAJE EN ORGANIZACIONES: UN CASO DE ESTUDIO}

\section{RESUMEN}

Este estudio se realizó sobre la base de la pregunta: «¿Cuáles son los aportes del proceso de analizar el entorno para el aprendizaje organizacional?" Buscando una respuesta, el estudio fue iniciado por una revisión de la literatura que trata sobre los conceptos clave y aplicaciones relacionadas con la forma en que el aprendizaje tiene lugar dentro de las organizaciones. Posteriormente se discute el teórico y conceptual en la literatura para los estudios sobre la estrategia de negocios de hoy. En el plano empírico, se presenta una investigación cualitativa que hace un estudio de caso en Petrobras, en que los datos se recopilaron mediante entrevistas. En primer lugar, presentamos los datos históricos y la descripción del análisis ambiental realizado en el proceso de planificación estratégica en la organización estudiada. A continuación, se presentan las opiniones de los directivos en relación con el aprendizaje derivado del proceso. Las declaraciones de los ejecutivos fueron clasificados por categorías y sometidos a análisis de contenido. Los resultados muestran que los consultados entienden que el análisis del medio ambiente es un medio de aprendizaje en la organización y dicen que que el aprendizaje contribuye al rendimiento del negocio mediante el desarrollo de sus habilidades para mejorar su actuación administrativa. Así, el estudio proporciona la visión de una asociación entre los procesos de planificación estratégica y el aprendizaje en las organizaciones.

Palabras clave: Análisis del medio ambiente; Aprendizaje Organizacional, Estrategia, Planificación Estratégica. 


\section{INTRODUÇÃO}

As transformações que afetam a sociedade mundial desafiam as organizações a buscar novas formas de lidar com a complexidade e a turbulência ambiental, idealizando seu futuro mediante estratégias que lhes permitam, no mínimo, sobreviver aos desafios proporcionados pela evolução do ambiente.

Diante da necessidade de adaptação, os indivíduos realizam o exercício de identificar novos fatos e analisá-los, atingindo um novo nível de conhecimento, o que, em essência, representa o resultado de um processo de aprendizagem. Dodgson (1993, p. 378) afirma que a aprendizagem organizacional tem sido vista como "uma busca proposital com o objetivo de reter e incrementar a competitividade, a produtividade, e a inovação em circunstâncias de incerteza tecnológica e de mercado”. A própria natureza evolutiva do ambiente conduz ao aprendizado, pois "quanto maiores as incertezas, maior a necessidade de aprender" (DODGSON, 1993, p. 378). Partindo dessa premissa, há indícios da associação entre esses dois fenômenos nas organizações modernas: a análise do ambiente e a aprendizagem organizacional.

A inquietação em relação ao tema provocou o interesse para a realização deste trabalho, pautado pelo problema de pesquisa assim enunciado: “Quais as contribuições do processo de análise do ambiente para a aprendizagem organizacional?"

Essa questão é estabelecida com base no pressuposto de que a análise do ambiente, tanto interno quanto externo, é efetuada no processo de planejamento estratégico por pessoas que integram a equipe de gestão da organização com o objetivo de identificar tendências futuras que irão desafiá-la à adaptação da organização a novas condições.

O objetivo geral é compreender "o quê" e "como" a organização aprende ao identificar e analisar essas tendências e "de que forma" essa aprendizagem é utilizada para a promoção de melhorias em situações futuras. Além do objetivo geral, dois objetivos específicos - descrever as atividades envolvidas na análise do ambiente pelos gestores entrevistados e identificar se eles reconhecem a aprendizagem como consequiência dessas atividades - foram propostos.

No plano empírico, a pesquisa recorreu à metodologia qualitativa, utilizando um estudo de caso, com foco nos gestores de uma empresa brasileira que participam do planejamento estratégico da organização. 
O processo de análise do ambiente e sua relação com a aprendizagem organizacional: um estudo de caso

\section{FUNDAMENTAÇÃO TEÓRICA}

Visando à compreensão do fenômeno da aprendizagem nas organizações e também do processo de análise ambiental, apresentam-se, a seguir, as visões conceituais e exemplificativas encontradas na literatura especializada e orientadoras da presente investigação.

\subsection{Aprendizagem nas organizações}

Os estudos sobre aprendizagem nas organizações figuram na literatura há mais de 40 anos. Popper e Lipshitz (2000) afirmam que grande parte dessa literatura é fragmentada e trata o tema em diferentes níveis de abstração. Ruas e Antonello (2003) indicam, por exemplo, a possibilidade de se dividir a literatura produzida mais recentemente em prescritiva e nãoprescritiva, observando a aprendizagem como resultado ou como processo. Há a que estuda as ‘organizações de aprendizagem', prático-orientada, de cunho prescritivo e, portanto, pouco crítica. Na corrente da 'aprendizagem organizacional' figuram os pesquisadores acadêmicos, de forma a conferir-lhe uma característica mais crítica e menos comprometida com ação ou resultados desejados, ou seja, sob uma ótica descritiva. Neste estudo o foco é direcionado à análise da aprendizagem organizacional como um processo, buscando a descrição e análise dos elementos presentes nesse fenômeno.

A aprendizagem organizacional, também, tem sido estudada a partir de seu caráter multidisciplinar que a torna alvo de estudos sob diferentes enfoques: psicológico, sociológico, antropológico, político, histórico e econômico. Esta diversidade de perspectivas está bem documentada em textos produzidos por Antonello e Godoy (2009, 2010) e Godoy e Antonello (2011). Antonello e Godoy (2010), baseando-se em Dierkes e colaboradores (2001) e em Easterby-Smith e Lyles (2003) resumem e analisam as contribuições de reconhecidos pesquisadores no campo da aprendizagem organizacional. Dentre elas destaca-se aqui a existência de estudos que remetem à concepção da aprendizagem como produto obtido a partir de ações intencionais da Administração. Para esta perspectiva a aprendizagem organizacional é observada sob o viés da Ciência da Administração que, de acordo com Pawlowsky (2001), reúne os autores que buscam fornecer elementos que auxiliem na compreensão do gerenciamento da aprendizagem nas organizações.

REAd I Porto Alegre - Edição 73 - Nº 3 - set/dez 2012 - p. $779-812$ 
A idéia de que uma organização é capaz de aprender por caminhos independentes aos dos indivíduos que a integram, proposta por Cyert e March (1963), representa um marco na evolução da literatura especializada sobre a aprendizagem nas organizações segundo uma visão gerencial. Os autores propõem uma teoria geral de aprendizagem organizacional como parte de um modelo de tomada de decisão da empresa, enfatizando as regras, procedimentos, convenções, estratégias e tecnologias - denominadas de rotinas por Levitt e March ( 1988) em torno das quais as organizações são organizadas, respondem aos desafios do ambiente externo e agem para se adaptar. A necessidade de adaptação, por sua vez, promove aprendizagem como resultado da aquisição de informações ou conhecimentos que os membros que integram a organização consideram úteis para a qualidade do desempenho organizacional.

Além do pioneirismo de Cyert e March (1963), as idéias de Argyris e Schön (1978), calcadas numa perspectiva cognitiva destaca a relevância do conhecimento acumulado e da informação para o processo da aprendizagem organizacional. Considera-se aqui que a aprendizagem organizacional é um processo por meio do qual os colaboradores detectam erros ou desvios e os corrigem, reestruturando, assim, a teoria em uso da organização. A aprendizagem organizacional é entendida como uma mudança que ocorre nas rotinas defensivas que fazem parte das organizações. Complementando pode-se destacar Kim (1993) que interpreta a aprendizagem organizacional como um aumento de capacidade da organização em apresentar ações efetivas. Assim,, o aprendizado de uma organização proporciona evolução, acompanhamento da dinâmica das forças competitivas e encorajamento do pensamento sistêmico.

Quando se entende a organização como um sistema de atividades coordenadas a contribuição de Senge (1990) se revela seminal. Para ele, quando se procura reduzir a complexidade de um sistema de rede, identificando e descrevendo as características dos fatores e das relações que o compõem, gera-se um conhecimento que pode ser usados para melhor compreender o funcionamento da rede, assim como para propor intervenções na mesma.

Ainda de acordo com Pawlowsky (2001) a perspectiva da Ciência da Administração tem recorrido aos autores que destacam a importância da aprendizagem na ação (Argyris e Schön, 1978) e entendem a aprendizagem organizacional enquanto a capacidade da organização manter ou melhorar seu desempenho baseando-se na experiência.

É importante pontuar que Antonello e Godoy (2010) acrescentam à perspectiva da Ciência da Administração apresentada por Pawlowsky (2001) a visão estratégica e gerencial que destaca 
O processo de análise do ambiente e sua relação com a aprendizagem organizacional: um estudo de caso

que a aprendizagem é fonte de heterogeneidade entre organizações, podendo se tornar uma possível vantagem competitiva, quando uma organização aprende mais rapidamente que outras. Nesta visão acredita-se que os gerentes desempenham papel fundamental neste processo na medida em que podem desenvolver ambientes de aprendizagem atentos a identificação de problemas que levem a tomada de decisões estratégicas com o objetivo de solucioná-los.

Com base na identificação das características que permitem agrupar as principais correntes conceituais da aprendizagem organizacional, Pawlowsky (2001) apresenta um modelo conceitual para o estudo da gestão da aprendizagem organizacional. De acordo com tal modelo, ilustrado pela Figura 1, essa gestão deve levar em consideração a ocorrência de aprendizagem em diversos níveis, modos, tipos e processos, que figuram como agentes integrados e inter-relacionados, como meios que conduzem ao que se descreve como aprendizagem organizacional.

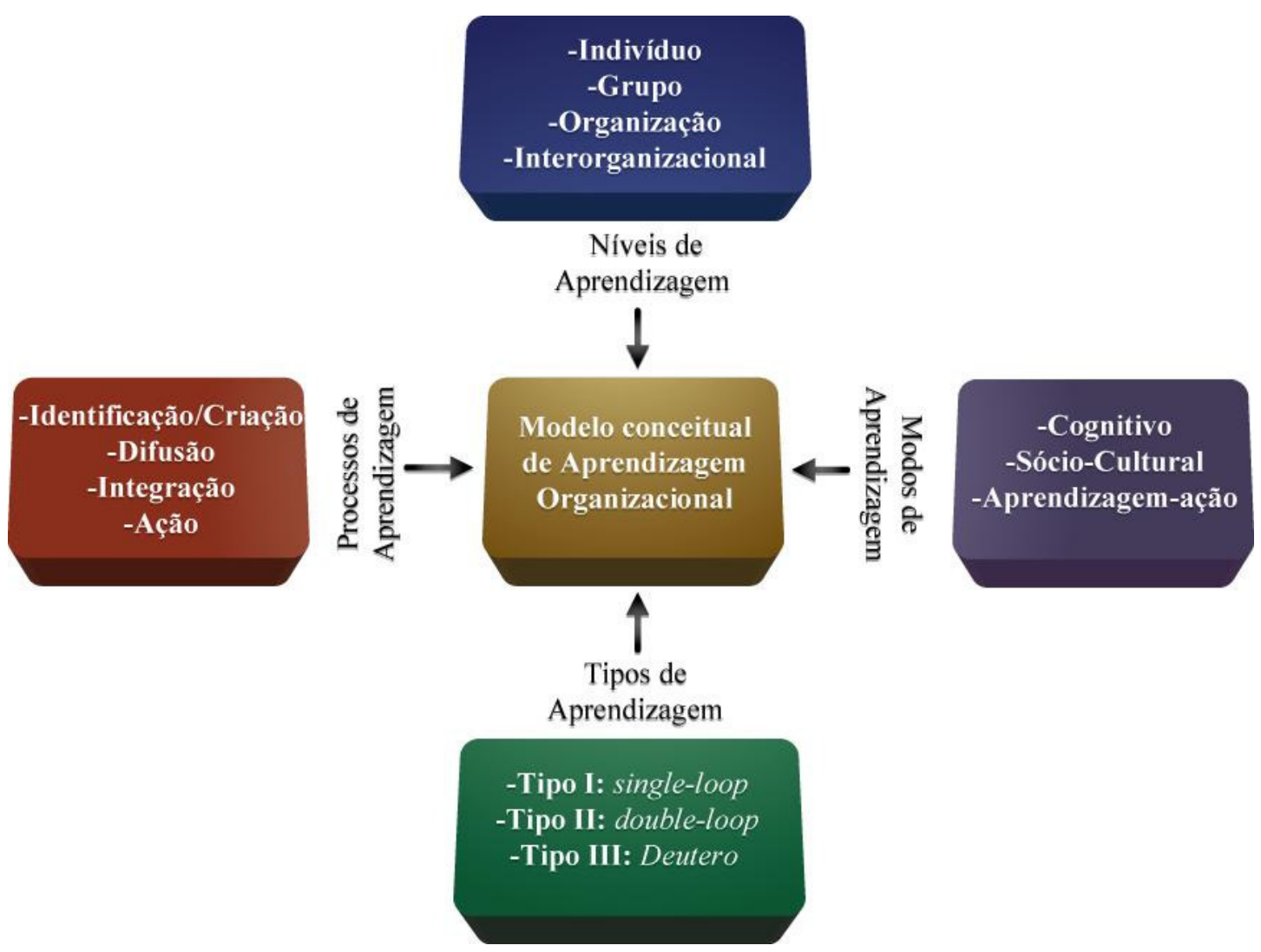

Figura 1. Um modelo conceitual para a gestão da aprendizagem organizacional Fonte: Pawlowsky (2001, p. 79).

Quanto aos níveis de aprendizagem, são comuns as alusões à aprendizagem individual, em grupo, organizacional ou mesmo entre organizações (DODGSON, 1993; CROSSAN; LANE; REAd I Porto Alegre - Edição 73 - Nº 3 - set/dez 2012 - p. $779-812$ 
WHITE, 1999; DEFILLIPPI; ORNSTEIN, 2003). De acordo com Kim (1993), a aprendizagem individual processa-se por intermédio de um ciclo em que o indivíduo assimila um dado novo, reflete a respeito de experiências passadas, chega a conclusões sobre o novo fragmento de informação e armazena essa informação em forma de modelos mentais. Para este autor, a aprendizagem individual se processa mediante ciclos de modificação e codificação das crenças nos modelos mentais dos indivíduos. Estes ciclos afetam a aprendizagem em nível organizacional por meio de sua influência nos modelos mentais compartilhados, traduzidos nas rotinas, memórias, procedimentos, que orientam as decisões, como um processo de transferência do aprendizado individual.

Na concepção de Kim (1993), a organização só pode aprender por meio dos seus membros, mas não depende de nenhum membro específico para que essa aprendizagem se realize. Os indivíduos entre os quais se dá a aprendizagem das organizações se agrupam em forma de equipes de trabalho, departamentos, subsidiárias e outros segmentos organizacionais. Ainda que não esteja permanentemente na organização, o indivíduo deixa, em sua passagem, o legado de sua aprendizagem nos grupos a que pertenceu. A influência exercida por um indivíduo particular ou por um grupo de indivíduos é determinante para que ocorra o compartilhamento dos modelos mentais individuais. Indivíduos gestores e grupos de gestão são influentes devido ao poder inerente às suas posições hierárquicas, mas isso não significa que um grupo numeroso de funcionários unidos não exerça influência nos modelos mentais compartilhados da organização. Por outro lado, o modo como a organização vê o mundo é um reflexo da sua cultura, suposições enraizadas, artefatos e regras de comportamento (KIM, 1993).

Apoiados numa abordagem sociocognitiva, Maier, Prange e Rosenstiel (2001) indicam que a capacidade de armazenagem de conhecimento dos grupos é superior à dos indivíduos, pois o conhecimento armazenado do grupo é a somatória dos fragmentos de conhecimentos armazenados por cada indivíduo que o compõe. Ou seja, a aprendizagem nas organizações inicia-se pelo nível dos indivíduos, cujo conhecimento é compartilhado com companheiros dos grupos e então disseminado pela organização, constituindo, assim, o que Huber (1991) descreve como a memória organizacional. São essas as principais referências conceituais assumidas para o presente estudo, que não se atém a questões relacionadas ao fenômeno em nível inter-organizacional, o qual, talvez por influência de estratégias de associações, incorporações e fusões entre organizações empresariais tem sido alvo de investigações que focam a troca de experiência e conhecimento entre duas ou mais organizações. 
O processo de análise do ambiente e sua relação com a aprendizagem organizacional: um estudo de caso

Quanto aos modos de aprendizagem nas organizações, existem, de acordo com Pawlowsky (2001), três diferentes perspectivas para a gestão da aprendizagem organizacional. A primeira delas é a cognitiva, que se baseia em teorias sobre a racionalidade no processo decisório das organizações, que atribui maior atenção à mudança de estruturas cognitivas dos sistemas de aprendizagem. A segunda é a perspectiva cultural, que representa uma abordagem da aprendizagem baseada em conceitos interpretativos do comportamento humano e inclui o pressuposto de que a realidade é construída socialmente pelo compartilhamento de significados, especialmente em relação a artefatos, símbolos, metáforas ou mitos. A terceira perspectiva, a de aprendizagem-ação, encontra suas raízes em conceitos de aprendizagem pela experiência e em abordagens sociotécnicas. Essas perspectivas correspondem a três instâncias existenciais da condição humana: o conhecimento, os sentimentos e a ação. Tais instâncias são assumidas por Pawlowsly (2001) como complementares quando se pretende promover a aprendizagem organizacional, de forma que para a gestão da aprendizagem é necessário compreendê-la não só como fruto de conhecimento, mas também de valores, emoções e comportamento. $\mathrm{O}$ autor destaca que pesquisas do campo da Psicologia Social indicam que a relação entre esses três componentes constitui um agente importante para a mudança de atitude, pois não basta aos participantes de uma organização compreender ou criar novas realidades. É preciso também que eles concordem em adotar novas visões e que se sintam aptos a agir em conformidade com elas. Com base na argumentação de Pawlowsky (2001) sobre a complementaridade dos três aspectos - conhecimento, sentimento e ação - e de sua importância para que se obtenha a efetividade do processo de aprendizagem organizacional, este estudo inclui a presença desses elementos na pesquisa de campo realizada.

Como referência para o estudo dos tipos de aprendizagem, Argyris e Schön (1978) consideram que a aprendizagem organizacional ocorre quando os membros da organização identificam erros ou anomalias, corrigem-nos, e assim promovem uma reestruturação da teoria em uso, advinda do comportamento individual que pode ser governado por regras formais ou informais. São exemplos os valores, as ações estratégicas e os pressupostos que orientam as rotinas e atividades da organização. Quando as conseqüências de uma ação não correspondem ao que se almejava, surge a oportunidade para a ocorrência de aprendizagem. Assim, a comparação entre o que se faz e o que se acredita ser o melhor a fazer, leva as pessoas, nas organizações, a aprenderem por meio de dois mecanismos: o aprendizado de circuito simples (single-loop learning) e o de circuito duplo (double-loop learning). 
Os indivíduos aprendem as normas de conduta organizacionais em uma aprendizagem cíclica, de circuito simples, a partir da qual podem interpretar de forma crítica o resultado de suas ações e propor melhorias, construindo assim a aprendizagem em circuito duplo.

A aprendizagem em circuito duplo, por sua vez, ocorre quando, além do erro ser detectado e corrigido, ocorre a modificação de normas, políticas e objetivos da organização. Ou seja, quando além da correção de erros a aprendizagem também abrange uma reflexão mais aprofundada sobre suas causas, princípios e orientações que permeiam as ações correntes na organização, obtém-se aprendizagem em circuito duplo, pois, assim, além da solução do problema, desenvolve-se também a capacidade de evitá-lo. Esse processo, segundo Argyris (1994), além de levar os empregados a aprenderem a refletir sobre a essência dos problemas, possibilita maior compreensão de como as pessoas pensam e quais razões ou regras cognitivas elas usam para agir.

Complementando a visão da ocorrência de diferentes tipos de aprendizagem, Argyris e Schön (1996) identificam o circuito triplo de aprendizagem, também denominado aprendizagem do tipo deutero. O circuito triplo ocorre quando os princípios essenciais da organização entram em discussão, provocando questões relacionadas ao que a organização pretende ser, quais contribuições deseja proporcionar, o que ela valoriza e assim por diante. Desse modo, ocorre uma aprendizagem que resulta no desenvolvimento de novos princípios organizacionais.

Em visão crítica complementar, Visser (2007) entende que a aprendizagem deutero refere-se à adaptação comportamental pelo condicionamento no nível de relações no contexto organizacional, ocorrendo de forma contínua, inconsciente e não como resultado de ações gerenciais explícitas. Ela não leva, necessariamente, a melhorias de resultados individuais ou organizacionais. Outro tipo de aprendizagem de circuito triplo seria a meta-aprendizagem, que se refere à reflexão e ao questionamento contido no processo de aprendizagem de circuito simples e duplo, tanto em nível individual como no nível das organizações. Trata-se de uma aprendizagem descontínua, cognitiva e consciente, com objetivo de melhoria de resultados em nível individual e organizacional. Há também, segundo Visser (2007), a aprendizagem planejada, que se refere à criação e manutenção de sistemas, rotinas, procedimentos e estruturas organizacionais em que os membros da organização são induzidos à metaaprendizagem em uma base regular, na qual os resultados da aprendizagem são utilizados como base para utilização futura. É possível notar, portanto, que a visão de Visser (2007) alerta para o fato de que, ao observar o fenômeno de aprendizagem segundo uma ótica gerencial, é preciso considerar se a intenção é identificar o caráter intencional da busca da 
O processo de análise do ambiente e sua relação com a aprendizagem organizacional: um estudo de caso

aprendizagem como meio de alcançar resultados mais favoráveis de desempenho organizacional.

Este estudo propõe-se a identificar a presença da aprendizagem em processos que abrangem desde a detecção de erros e suas causas até a proposta de novos rumos, em decorrência do estabelecimento de estratégias organizacionais. Destarte, a presença dos três tipos de aprendizagem descritos por Argyris e Schön (1996) é objeto de análise. Não se deixa de considerar que a aprendizagem em circuito triplo deve ser analisada sob as três formas diferentes expostas por Visser (2007).

A visão da aprendizagem organizacional como processo levou Pawlowski (2001) a considerar a necessidade de identificação dos passos a partir dos quais os processos de aprendizagem ocorrem. Pawlowsky (2001) apresenta uma descrição do processo segundo o qual se concretiza a aprendizagem organizacional, sugerindo quatro passos, não necessariamente seqüenciais. O primeiro passo é a identificação da informação que parece relevante para a aprendizagem, para a criação do conhecimento ou para ambos. Outro passo é a troca e a difusão do conhecimento, tanto no nível individual quanto no coletivo. Um terceiro passo seria a integração do conhecimento a sistemas de conhecimento já existentes, também em ambos os níveis, individual e coletivo. Por fim, Pawlowsky (2001) identifica um quarto passo, representado pela transformação do novo conhecimento em ação, aplicando-o às rotinas da organização de forma a impactar no comportamento organizacional.

Nota-se, portanto, que a Ciência da Administração aborda o fenômeno da aprendizagem nas organizações sob diferentes concepções e enfoques. Como forma de direcionar este estudo ao seu foco de análise, assume-se por referência conceitual, os seguintes pressupostos: a aprendizagem nas organizações corresponde ao aumento da capacidade em apresentar ações efetivas de melhoria de desempenho (KIM, 1993), que é obtida pelo aperfeiçoamento das ações, compreensão, conhecimento (FIOL; LYLES, 1985) e processamento de informações (HUBER, 1991). Isto se dá por meio da detecção de erros (ARGYRIS; SCHON, 1978) e da aquisição de novos conhecimentos pelos indivíduos, a seguir compartilhados com o grupo e disseminados pela organização (KIM, 1993); as teorias em uso e os comportamentos potenciais da organização são sucessivamente modificados, caracterizando, assim, um processo evolutivo em que ocorre aprendizagem (PAWLOWSKI, 2001). Esse processo, por sua vez, pode ser facilitado ao se proporcionar um ambiente favorável ao seu desenvolvimento na organização (ARGYRIS, 1994; BAPUJ; CROSSAN, 2004). 
Em uma revisão da literatura internacional a respeito da aprendizagem organizacional Bapuj e Crossan (2004) detectaram o aumento significativo de estudos empíricos sobre o tema, muitos deles conduzidos por autores que realizam pesquisas na área de estratégias e que empregaram as teorias da aprendizagem para examinar questões associadas ao desempenho organizacional. Destacam ainda neste estudo seis fatores contextuais que afetam a aprendizagem nas organizações: cultura, estratégia, estrutura, ambiente, estágio de desenvolvimento da organização e recursos. Em relação ao tema da estratégia os estudos desenvolvidos reafirmam que a postura estratégica de uma organização influencia a aprendizagem organizacional ao prover um contexto que auxilia na percepção e interpretação do ambiente. Os resultados encontrados mostraram que indústrias farmacêuticas que enfatizavam aprendizagem radical e incremental, assim como aprendizagens internas e externas, apresentavam resultados mais satisfatórios (BIERLY; CHAKRABARTI,1996). Foram ainda identificadas outras estratégias que facilitam que a aprendizagem organizacional aconteça. Segundo Kim (1998) é possível gerar crises visando estabelecer um gap de desempenho, mudando assim o curso da organização no sentido de buscar a inovação e aprendizagem. Constituem-se ainda estratégias que levam á aprendizagem a ampliação das fronteiras da tecnologia e da própria firma (ROSENKOPT; NERKAR, 2001) e o compartilhamento do conhecimento com sistemas de inovação nacionais e global (SPENCER, 2003).

No caso da produção nacional o relato feito por Godoy e Antonello (2011) mostra que apenas 12 estudos, dos 94 artigos analisados envolvendo o período 2001-2005, identificaram e analisaram novos modelos de gestão que buscaram estabelecer interface com a gestão da qualidade, da inovação, de recursos humanos, de produção, e/ou de estratégias, visando enfrentar os desafios colocados pelas novas ambiências dos negócios.

\subsection{Análise ambiental no planejamento estratégico nas organizações}

Segundo Ghemawat (2000), na década de 1950, ocorreu um desenvolvimento paralelo da discussão sobre a adequação da estratégia de empresas em relação ao ambiente de negócios e à utilização do planejamento como forma de buscar melhores condições de sobrevivência das empresas. Outro passo reconhecido como importante na literatura sobre a estratégia aplicada ao comportamento das organizações foi dado quando se propôs a técnica de análise denominada SWOT (Strengths, Weaknesses, Opportunities, Threats). Concebida pela Escola de Harvard na década de 1950, a análise SWOT fundamentou-se na preocupação com a 
O processo de análise do ambiente e sua relação com a aprendizagem organizacional: um estudo de caso

identificação do negócio em que a empresa irá atuar. Caracteriza-se como um modelo que tem como principal resultado o despertar do senso crítico dos gestores para a necessidade de adaptação da organização ao seu meio ambiente. No início dos anos 60 , começaram a ser discutidas as possíveis combinações entre oportunidades, riscos e recursos corporativos como determinantes da escolha da estratégia econômica mais adequada para os negócios. $\mathrm{O}$ planejamento de longo prazo, como era denominado até então, foi sendo gradativamente substituído, nas empresas, pelo Planejamento Estratégico. Mintzberg (1973) argumenta que a estratégia não pode ser definida em termos estáticos, pois forças, fraquezas, oportunidades e ameaças são muito relativas no tempo. Assim, introduziu-se a noção de mudança na estratégia, questionando o caráter demasiado estático da análise SWOT. As forças e fraquezas, no plano interno de análise, começam a ser vistas como motores ou freios que mudam com o tempo, em função de outras variáveis.

O reconhecimento do dinamismo ambiental incita a refletir sobre possíveis situações futuras, para o melhor ajuste das reações da empresa. Esse fato talvez explique a crescente utilização de métodos de previsão, quer sejam os prospectivos, em que se extrapola o passado para o futuro, ou os que partem do futuro para construir o presente (MINTZBERG, 1973).

A evolução histórica do pensamento estratégico aplicado à Administração revela a presença constante de duas perspectivas centrais: a que se preocupa com o ambiente externo e a que enfatiza o desenvolvimento de meios para melhor utilizar os recursos da empresa. A teoria sobre a Estratégia Empresarial, na atualidade, serve-se da combinação dessas duas perspectivas em que reside o êxito das estratégias organizacionais. Para Mintzberg e Quinn (2001), os processos de mudança nas organizações são fragmentados, evolucionários e intuitivos, de forma que "a verdadeira estratégia evolui à medida que decisões internas e eventos externos fluem juntos para criar um novo e amplamente compartilhado consenso para as providências a serem tomadas"(p. 108).

Modelos que descrevem o processo de planejamento estratégico encontrados na ampla literatura sobre estratégia aplicada à gestão trazem perspectivas diversificadas sobre as etapas do processo e sua aplicação (MINTZBERG, 1973; ACKOFF, 1976; LORANGE; VANCIL, 1976, ANSOFF, 1977; ANDREWS, 1971; GLUCK; KAUFMAN; WALLECK, 1980; PORTER, 1986; MINTZBERG; QUINN, 2001; CHAKRAVARTHY; WHITE, 2002, CERTO et al., 2005).

Analisando as diversas abordagens encontradas na literatura sobre estratégia, Mintzberg, Ahlstrand e Lampel (2000) indicam alguns pontos de convergência, que contribuem para uma 
visão mais abrangente do conceito adotado neste trabalho. Um deles é o de que a estratégia pode ser uma forma deliberada ou não de a empresa lidar com mudanças do ambiente, o que implica na necessidade do diagnóstico estratégico, que compreende o levantamento de informações sobre a organização e o ambiente no qual está inserida. Além disso, a complexidade figura como característica intrínseca da estratégia, em face da multiplicidade de combinações possíveis de variáveis.

Ainda segundo Mintzberg, Ahlstrand e Lampel (2000), os estudos sobre estratégia podem ser classificados em dez escolas com diferentes enfoques sobre a formulação de estratégias: a escola do design, que vê a formulação de estratégias como processo de concepção, a do planejamento, que enfatiza o planejamento formal, a do posicionamento, em que as estratégias resultam de um processo analítico, a empreendedora, para a qual as estratégias decorrem de um processo visionário, a cognitiva, que vê as estratégias como resultado de processo mental, a de aprendizagem, que concebe a formulação de estratégias como um processo emergente, a do poder, segundo a qual a estratégia é negociada, a cultural, em que a formulação de estratégias é vista como processo coletivo, a ambiental, que considera as estratégias como reação ao ambiente e, por último, a de configuração, que interpreta as estratégias como resultantes de um processo de transformação.

Neste trabalho, em virtude da especial atenção que se pretende atribuir à presença de processos de aprendizagem organizacional na análise ambiental destinada à formulação de estratégias, a ênfase recai sobre duas escolas: a cognitiva e a de aprendizagem.

$\mathrm{Na}$ escola cognitiva assume-se que por trás do processo de análise da situação para a formulação de estratégias em uma organização, existem indivíduos com valores e crenças que tendem a limitar sua capacidade de entendimento do mundo, de forma que para se compreender o processo é preciso estudar a mente do estrategista. Em geral, existe uma disposição de buscar fatos que conduzem a uma conclusão mais alinhada às crenças do estrategista e desprezar outros que possam ameaçá-la.

Além dessa característica presente nos indivíduos que efetuam a análise situacional para a formulação de estratégias nas organizações, a escola cognitiva assume que os critérios de decisão em situações semelhantes dificilmente são os mesmos. Tal fenômeno decorre, principalmente, do caráter evolutivo das pessoas à medida que desenvolvem novos conhecimentos, embora, paradoxalmente, elas tendam a ver os problemas a partir da percepção gerada pela situação vivenciada anteriormente. 
O processo de análise do ambiente e sua relação com a aprendizagem organizacional: um estudo de caso

A escola que focaliza a aprendizagem, por sua vez, concebe as grandes mudanças estratégicas como frutos da consistência de pequenas ações e decisões de várias pessoas, dos mais diversos níveis hierárquicos, ao longo do tempo. Conforme concluem Mintzberg, Ahlstrand e Lampel (2000), sob a ótica da escola de aprendizagem todos, em uma organização, podem ser estrategistas. Tal premissa se revela quando uma organização constitui um ou mais grupos de pessoas dedicadas à elaboração de cenários futuros e de diretrizes estratégicas organizacionais que orientarão o processo decisório, em que se observam resultados a alcançar diante de desafios proporcionados pelo ambiente organizacional.

\subsection{Aprendizagem na análise e interpretação do ambiente externo e interno das organizações}

A associação dos conceitos que sustentam os estudos sobre estratégia aplicada à administração de organizações aos processos de aprendizagem tem provocado trabalhos que discutem a visão da estratégia como um processo de aprendizagem (MUMFORD, 2000; THOMAS; SUSSMAN; HENDERSON, 2001; HEDBERG; WOLFF, 2001; CHAKRAVARTHY; WHITE, 2002; HODGKINSON, 2002; SCHAFFER; WILLAUER, 2003), a importância da aprendizagem para a renovação estratégica das organizações (CROSSAN; BERDROW, 2003), o nexo entre o planejamento estratégico e a aprendizagem organizacional (ENDLICH, 2001), ou mesmo os elementos que simultaneamente dificultam a implementação de estratégias e a aprendizagem (BEER; EISENSTAT, 2000). Embora todos os autores mencionados apresentem evidências empíricas da associação entre os dois fenômenos, procuram-se destacar algumas dessas abordagens que se alinham às referências conceituais adotadas neste estudo.

Visando a comprovar a influência direta entre o processo de planejamento estratégico e a aprendizagem, Schaffer e Willauer (2003) elaboraram um modelo de pesquisa que testa, estatisticamente, relações empíricas entre elementos do processo de aprendizagem e de formulação de estratégias em empresas na Alemanha. Com base em teorias de aprendizagem cognitivas e sociais, os autores descrevem o processo de aprendizagem organizacional como um ciclo cibernético alimentado pelo feedback obtido quando os modelos internos são modificados. 
No processo, os membros de uma organização modificam sua interpretação dos eventos e a compartilham, caracterizando mudança dos modelos internos pela aprendizagem. Isso acaba se tornando, segundo Schaffer e Willauer (2003), o papel principal do planejamento estratégico, considerando que este busca melhor desempenho futuro com base em sucessos e fracassos do passado associados à análise de cenários prováveis.

Hedberg e Wolff (2001) argumentam que as estratégias talvez possam ser simplesmente descobertas, quer seja por compreender situações retrospectivas ocorridas na própria organização ou por meio de imitação de estratégias de outros. Segundo os autores, o planejamento estratégico, do modo racional como se propunha nas décadas de 1960 e 1970, seria um processo de aprendizagem em circuito simples, pois nele as decisões ocorrem com base em estímulos e interpretações de situações passadas. Hedberg e Wolff (2001) lembram que a vasta literatura sobre estratégia aplicada à gestão comumente enfatiza que as organizações aprendem a partir de sucessos e reforçam comportamentos bem-sucedidos, o que conduz a melhorias do desempenho organizacional. Também é fato que alguns pesquisadores reconhecem que as crises, as falhas e os riscos potenciais de suas organizações e de outras representam um grande aprendizado. O resultado é a aprendizagem em circuito duplo proporcionada pela descoberta decorrente da prática do planejamento.

A partir da crítica que estabelecem em relação à ausência de uma teoria unificada que conecte as múltiplas perspectivas dos estudos da estratégia empresarial, Chakravarthy e White (2002) apresentam um modelo do processo estratégico nas organizações em que se considera a aprendizagem em circuito duplo como causa e efeito da formulação e implementação de estratégias. A compreensão do contexto de negócios, no qual se incluem a análise do ambiente e a identificação de competências centrais, gera uma aprendizagem que influencia diretamente o contexto organizacional e, conseqüentemente, o processo decisório na formulação das estratégias. Uma vez implementadas, essas estratégias conduzem a um desempenho cujo conhecimento realimentará, por sua vez, o mesmo contexto organizacional e o processo decisório, dando origem a novas estratégias, de forma a fechar o ciclo de aprendizagem em circuito duplo.

Os aspectos acima apontados denotam a presença de indícios de que o processo de análise e diagnóstico presente no planejamento estratégico e a aprendizagem organizacional andam juntos em diversas situações vivenciadas pelas organizações.

A associação dos componentes da aprendizagem aos que se observam no processo de análise ambiental para a formulação de estratégias, com base no que se pretende analisar para a 
O processo de análise do ambiente e sua relação com a aprendizagem organizacional: um estudo de caso

realização dos objetivos deste estudo, conduz a um modelo conceitual em que se assume, como referência para a pesquisa, que o exercício de análise do ambiente externo e das condições internas da organização provoca uma mudança nos modelos mentais existentes devido à ocorrência de aprendizagem. Os novos modelos conduzem à formulação e implementação de novas estratégias, decorrentes da aprendizagem nos níveis individual e organizacional, que, por sua vez, influenciarão as atitudes dos gestores quando estes reiniciarem o processo de análise externa e interna.

\section{ASPECTOS METODOLÓGICOS}

Para a realização do presente estudo escolheu-se a metodologia qualitativa, com base no paradigma interpretativo descrito por Merriam (1998). Acredita-se que essa escolha tenha sido a mais adequada porque a aprendizagem organizacional se caracteriza como um fenômeno construído socialmente a partir de processos de interpretação e processamento de informações.

O estudo se desenvolveu com propósitos exploratório e descritivo. Recorreu-se a um Estudo de Caso desenvolvido de acordo com as etapas propostas por Hartley (1994): (a) escolha do caso; (b) conquista e manutenção do acesso ao caso; (c) escolha de um modelo teórico inicial; (d) coleta sistemática de dados; (e) gerenciamento da coleta de dados; (f) análise dos dados; (g) saída do estudo de caso.

A escolha do caso para estudo recaiu em uma empresa de grande porte, atuante em uma indústria monopolista e que aparentemente não deve se preocupar em desenvolver conhecimento ou inovar como forma de ser mais competitiva, mas que declara preocupação com a aprendizagem organizacional: A Petrobras, organização genuinamente brasileira, o que confere à pesquisa um caráter investigativo regional, motivado, principalmente, pela escassez de estudos sobre aprendizagem em organizações em que os padrões culturais não são os norte-americanos. O caso selecionado pode ser considerado crítico para o estudo da aprendizagem organizacional pelo fato de a empresa operar em várias atividades e assim se fragmentar em diversas unidades de negócios com características distintas, mas ao mesmo tempo integradas em torno da formulação e implementação de estratégias. Tal fragmentação, além de impor a necessidade de instalação das bases administrativas em diversas localizações geográficas, também ocasiona um distanciamento natural nas ações cotidianas dos gestores, o que dificulta a convivência entre esses profissionais, que devem, contudo, agir de uma forma 
fundamental para o cumprimento dos objetivos estratégicos. A escolha também se justifica por três características da dinâmica de formulação e implementação de estratégias da empresa: (1) os desafios ambientais, tais como a instabilidade do mercado mundial no setor petrolífero, a queda do monopólio das estatais e as crises políticas internacionais; (2) a divulgação constante das principais estratégias ao público (PETROBRAS, 2011) e (3) a representatividade, por se posicionar, há vários anos, como a maior empresa brasileira em diversos quesitos, tais como patrimônio líquido, receita, lucro líquido, criação de riqueza, pagamento de salários e geração de impostos (EXAME, 2011).

Identificou-se a existência de uma área especializada denominada Estratégia e Desempenho Empresarial. Conseguiu-se um primeiro contato telefônico com um executivo daquela área, no qual foi exposta a idéia central do trabalho. Procedeu-se, então, a uma entrevista a título de estudo-piloto, na qual se obteve uma descrição detalhada do processo de planejamento estratégico e de seus participantes, alguns documentos internos utilizados nesse processo. Buscou-se também informações em outras fontes, tais como revistas e sítios na internet especializados em notícias e informações da indústria do Petróleo e, em especial, o próprio sítio da companhia, o que possibilitou conhecer alguns fatos atuais e históricos alí descritos.

Para a seleção dos sujeitos da pesquisa foram realizados os três passos sugeridos por AlvesMazzotti (2002): (a) a identificação dos participantes iniciais, feita com a ajuda de informantes que conhecem o contexto estudado; (b) a seleção de novos sujeitos à medida que já se tenham obtido as informações dos sujeitos previamente selecionados, de forma a complementar ou testar as informações já obtidas e (c) inclusão de novos sujeitos mais relacionados com questões emergentes durante a análise dos dados colhidos.

De acordo com Johnson (2002), o número ideal de entrevistas é o quanto o pesquisador ache suficiente para descobrir e verificar o que procura, inclusive retornando a alguns dos informantes em que mais confie ou que aparentemente detenham maior conhecimento sobre o assunto para esclarecer um tópico específico. A intenção, dessa forma, não é obter uma amostra significativa de uma população, mas escolher entrevistados com maior potencial de fornecer as informações desejadas. A partir dessa orientação, foram selecionados, com base em critérios como a acessibilidade e a experiência de participação na análise ambiental da empresa, dezesseis sujeitos, todos profissionais que atuam há mais de duas décadas na empresa e integrantes do grupo de planejamento estratégico, a quem se entrevistou em seu local de trabalho.

As dezesseis entrevistas, realizadas no período compreendido entre 28/11/2006 e 02/05/2007, foram gravadas e transcritas literalmente, para posterior análise, e acompanhadas de anotações 
O processo de análise do ambiente e sua relação com a aprendizagem organizacional: um estudo de caso

efetuadas no caderno de campo, provenientes de observações do entrevistador e de diálogos informais mantidos com os entrevistados antes e depois das entrevistas.

Tendo como principal direcionador o problema de pesquisa e os objetivos estabelecidos para o trabalho, elaborou-se um roteiro que permitisse conferir à entrevista um caráter semiestruturado. O tratamento dos dados obtidos nas entrevistas foi efetuado de acordo com a metodologia de template analysis (King, 1998), também conhecida por Codificação Temática (Thematic Coding), apoiada pela utilização do programa de computador Nvivo, versão 7.0. Procedeu-se à categorização de todo o material transcrito e interpretaram-se as respostas dos entrevistados, visando à associação da forma pela qual os respondentes vêem as práticas da empresa com relação às dimensões-chave propostas no referencial teórico. Com base nas categorias previamente emergentes em decorrência da construção do roteiro semi-estruturado e dos resultados obtidos nas entrevistas,foram adotadas seis categorias de análise: $1^{\mathrm{a}}$.) papel dos entrevistados no processo de planejamento estratégico; $2^{\mathrm{a}}$.) aprendizagem decorrente do planejamento estratégico; $3^{\mathrm{a}}$.) processo de análise do ambiente externo; $4^{\mathrm{a}}$.) aprendizagem decorrente da análise do ambiente externo; $5^{\mathrm{a}}$.) processo de análise do ambiente interno; e $6^{\mathrm{a}}$.) aprendizagem decorrente da análise do ambiente interno.

$\mathrm{Na}$ apresentação e discussão dos resultados utilizou-se, a título ilustrativo, citações de alguns trechos das declarações dos entrevistados, conforme recomenda Eisenhardt (1989). Para preservar a identidade dos participantes, eles são citados como E_01 (entrevistado 1), E_02 (entrevistado 2), e assim sucessivamente, até o E_16 (entrevistado 16).

\section{APRESENTAÇÃO E DISCUSSÃO DOS RESULTADOS DA PESQUISA}

Em consonância com a própria evolução histórica da companhia, o processo de planejamento estratégico praticado por sua equipe gestora vem se desenvolvendo e aperfeiçoando. Até a mudança no modelo regulatório da indústria no País, em 1998, a missão da companhia se resumia a "abastecer o país com petróleo e derivados aos menores custos para a sociedade" (PETROBRAS, 2006). Com a nova regulamentação do setor petrolífero no Brasil, a Petrobras foi impelida a ter, em sua filosofia empresarial, a consciência para os fatores característicos de seu novo ambiente de negócios, em que surgia a possibilidade de vir a competir com outras empresas de petróleo. Foi, nessa fase, que o então presidente da Petrobras decidiu convocar seus colaboradores para a implementação do que se pratica até os dias atuais com relação ao planejamento estratégico da companhia.

REAd I Porto Alegre - Edição 73 - Nº 3 - set/dez 2012 - p. $779-812$ 
O atual Estatuto da empresa, aprovado pelo Conselho de Administração em 2002, regulamenta e sistematiza a participação das diversas áreas no planejamento estratégico. Esse documento confere legitimidade ao Comitê de Negócios da Petrobras, com a finalidade de: "Ser um fórum de integração dos assuntos relevantes e estratégicos, visando promover o alinhamento entre o desenvolvimento dos negócios, a gestão da Companhia e as diretrizes do Plano Estratégico da Petrobras". Além do Comitê de Negócios, a Petrobras institucionalizou, por meio do Estatuto Social de 10/06/2002, aprovado pela Assembléia Geral Extraordinária, a participação de sua Diretoria Executiva e do próprio Conselho de Administração no Planejamento Estratégico da companhia. Cabe à primeira legitimar as estratégias propostas pelo Comitê de Negócios e ao segundo aprovar o Plano Estratégico, bem como os respectivos Planos Plurianuais e Programas Anuais de Dispêndios e de Investimentos.

Fundamentalmente realizadas com base em entrevistas efetuadas com integrantes do Comitê de Negócios da empresa, os dados da pesquisa revelam o papel dos entrevistados no processo de planejamento estratégico, objeto de análise na primeira categoria estabelecida para o estudo. As entrevistas também revelam a visão que eles possuem da aprendizagem decorrente do planejamento estratégico, segunda categoria de análise. Na terceira e quarta categorias de análise identificam-se, respectivamente, como se processa a análise do ambiente externo e a aprendizagem decorrente desse processo. Já na quinta e sexta categorias, obtêm-se a descrição do processo de análise do ambiente interno e a aprendizagem decorrente da análise do ambiente interno. Nos tópicos seguintes apresenta-se a discussão dos resultados obtidos em cada uma dessas categorias de análise e, na seqüência, uma reflexão sobre esses resultados à luz do modelo conceitual de Pawlowski (2001), eleito como balizador deste estudo no que se refere aos processos de aprendizagem nas organizações.

\subsection{Participação dos entrevistados no processo de planejamento estratégico}

Na primeira categoria de análise, referente à participação dos entrevistados no processo de planejamento estratégico, que todos eles são integrantes do Comitê de Negócios. Este órgão tem atribuições de recomendar propostas para a Direção, analisar temas relevantes, discutir, formular e propor diretrizes a serem aplicadas nas várias áreas da companhia e definir as necessidades de informações e análises para a tomada de decisão com qualidade nos temas relevantes e estratégicos para a empresa. O Diretor Gerente da área de Estratégia e Desempenho Empresarial é o secretário executivo do comitê, composto, também, pelo 
O processo de análise do ambiente e sua relação com a aprendizagem organizacional: um estudo de caso

presidente da companhia, seis diretores e trinta e cinco gerentes executivos das diversas áreas. O Comitê de Negócios reúne-se semanalmente, com o objetivo de constituir um fórum onde seus participantes recebem e discutem as mais variadas informações sobre o mercado e outras tendências. Diversos dos entrevistados descrevem esse processo, conforme ilustra, por exemplo, a fala de E_16:

[...] nós somos convidados às reuniões de preparação do planejamento estratégico, daí a nossa contribuição [...] a gente tem ali ampla liberdade de opinar, os cenários, como que essa coisa aconteceu, se aconteceu ou não, como que nós estamos sentindo o mercado, como nós estamos sentindo o fornecedor [...](E_16).

A cada início de ano, deflagra-se uma revisão formal do planejamento estratégico, iniciandose, assim, uma série de etapas que se desenvolvem nos meses subseqüentes mediante um calendário formal. Ao final de cada um desses ciclos anuais, são produzidos os Planos de Negócios, integrados ao Plano Estratégico Corporativo, em que se enfatizam a Visão de futuro aplicada a um período de longo prazo e a Missão corporativa, revista e adequada a essa nova visão.

\subsection{Aprendizagem decorrente do planejamento estratégico}

Nota-se a presença de aprendizagem no planejamento estratégico, que é objeto da segunda categoria de análise, quando se observa a evolução do produto gerado por esse processo. No plano vigente até julho de 2007, por exemplo, apresentavam-se como Visão e Missão:

Visão 2015: A Petrobras será uma empresa integrada de energia com forte presença internacional e líder na América Latina, atuando com foco na rentabilidade e na responsabilidade social e ambiental.

Missão: Atuar de forma segura e rentável, com responsabilidade social e ambiental, nas atividades da indústria de óleo, gás e energia, nos mercados nacional e internacional, fornecendo produtos e serviços adequados às necessidades dos seus clientes e contribuindo para o desenvolvimento do Brasil e dos países onde atua. (PLANO DE NEGÓCIOS PETROBRAS 2015, 2007).

Em agosto de 2007, como produto da revisão efetuada pelo Comitê de Negócios ao longo do exercício de planejamento 2007, essas diretrizes foram alteradas para:

Visão 2020: Seremos uma das cinco maiores empresas integradas de energia do mundo e a preferida pelos nossos públicos de interesse.

Missão: Atuar de forma segura e rentável, com responsabilidade social e ambiental, nos mercados nacional e internacional, fornecendo produtos e serviços adequados às necessidades dos clientes e contribuindo para o desenvolvimento do Brasil e dos países onde atua. (PLANO ESTRATÉGICO PETROBRAS 2020, 2007).

Também dentre os depoimentos dos entrevistados, nota-se a consciência para a aprendizagem decorrente do processo de planejamento estratégico:

REAd I Porto Alegre - Edição 73 - N 3 - set/dez 2012 - p. 779-812 
[...] quem participa desse processo tem como subproduto um ganho de conhecimento da organização e também do contexto em que ela vive. [...] todas as pessoas que participam ganham muito nesse processo, como aprendizado (E_02).

[...] acrescenta muito porque você começa a ter uma visão geral da companhia [...], isso é importante dentro do seu processo decisório da área que você é responsável (E_03).

[...] o grande aprendizado é na visão espacial, é como você ver a corporação de uma maneira mais ampla, integrada, entender os diversos negócios (E_10).

[...] cada processo desse a gente vê mais um aspecto da organização que ela é muito grande, muito complexa então é impossível uma pessoa ter domínio sobre tudo o que acontece, não existe. Cada vez que a gente tem um olhar sobre isso a gente faz aprendendo mais coisas e aprendendo mais coisas vai trazendo, aportando para estratégias um refinamento e um olhar um pouco diferenciado, mas complexo também (E_12).

[...] a empresa é tão grande, tão diversificada que você não consegue acompanhar tudo o que está sendo feito, então [...] aquilo ali no momento da formulação da estratégia tem o aprendizado do entender outras questões que não estão no dia a dia dele (E14).

Conforme se observa, os entrevistados vêem o processo como oportunidade para o desenvolvimento de uma visão sistêmica da organização, fruto do compartilhamento do conhecimento entre indivíduos de diversas áreas, o que confirma algumas premissas da escola de aprendizagem, descritas por Mintzberg, Ahlstrand e Lampel (2000). Dentre essas premissas, podem-se destacar duas, em especial: a que considera o efeito da complexidade decorrente da multiplicidade de variáveis e agentes ambientais em uma relação contínua de aprendizagem por todos os níveis da organização; e a que entende a aprendizagem como resultado da análise do acontecido para que se possa compreender a ação.

\subsection{Processo de análise do ambiente externo}

A estrutura e o processo observados confirmam o que se identificou na literatura, na qual apesar de se encontrarem perspectivas diversificadas sobre as etapas do processo e sua aplicação dependendo do autor (MINTZBERG, 1973; ACKOFF, 1976; LORANGE; VANCIL, 1976, ANSOFF, 1977; ANDREWS, 1980; GLUCK; KAUFMAN; WALLECK, 1980; PORTER, 1986; MINTZBERG; QUINN, 1991; CHAKRAVARTHY; WHITE, 2002, CERTO et al., 2005), todos consideram que ele principia pelo diagnóstico estratégico, estabelecido a partir da análise do ambiente externo e das condições internas da organização.

A terceira categoria de análise remete à análise do ambiente externo. Conforme se constata nas entrevistas, são temas freqüentes dessa análise questões tecnológicas, políticas, econômicas ou outros assuntos de cunho estratégico. 
O processo de análise do ambiente e sua relação com a aprendizagem organizacional: um estudo de caso

[...] tem fóruns permanentes de discussão e a gente chama pessoas que têm visão de futuro e estão sintonizadas na área econômica, na área política, na área do negócio em si, [...] e a gente está permanentemente chamando essas pessoas e botando isso em fóruns de discussão (E_02).

após [...] definir e discutir quais seriam os cenários em nível externo, os cenários corporativos, [...] nós definimos os nossos cenários focais (E_05).

[...] na condução do processo do projeto de estratégia corporativa, monitoramento de cenários [...], através de cenários [...], muito focado na questão de [...] prever o tamanho de mercado, preços, margem [...]. Então é basicamente ai que no nível de atividade econômica, mundial, América do Sul, contas de integração entre hedges na América do Sul, principalmente o gás, e finalmente Brasil (E_08).

\subsection{Aprendizagem decorrente da análise do ambiente externo}

Segundo a visão da escola de formulação estratégica cognitiva, descrita por Mintzberg, Ahlstrand e Lampel (2000), as estratégias emergem como processos cognitivos na mente das pessoas, em função de como elas lêem e reúnem as informações vindas do ambiente. Esse foi o objeto da quarta categoria de análise, que enfoca a presença da aprendizagem nas ações destinadas à análise do ambiente externo. A formulação de estratégias da Petrobras é efetuada com base em uma prospecção de tendências ambientais que leva os participantes do Comitê de Negócios a estabelecer três cenários alternativos como referência para a formulação de estratégias corporativas da empresa. Elege-se, então, o cenário mais provável e a partir dele se consideram os desdobramentos para os cenários focais de cada unidade de negócios.

[...] você começa a ter uma visão geral da companhia grande, você começa a entender a companhia, isso é importante dentro do seu processo decisório da área que você é responsável (E_03).

[...] na questão do aprendizado na organização é fundamental processo de desdobramento para que a gente possa envolver nesse aprendizado pessoas que tem um nível de participação diferente e se põe em discussão (E_13).

[...] o que mais a gente aprende é fazer, realmente, uma abstração daquilo que é muito concreto, que você está vivendo num curto espaço de tempo, sabe? Você começa a projetar mais adiante as possibilidades. (E_16).

\subsection{Processo de análise do ambiente interno}

A quinta categoria de análise, voltada para o processo de análise do ambiente interno organizacional, revela que tal análise é direcionada ao desempenho atual e não se restringe à periodicidade com que é revisto o plano estratégico, mas ocorre de forma constante por meio de indicadores de desempenho. Isso decorre da preocupação dos gestores em verificar se REAd I Porto Alegre - Edição 73 - Nº 3 - set/dez 2012 - p. 779-812 
internamente a empresa está devidamente estruturada para enfrentar os desafios proporcionados pelas mudanças ambientais.

[...] todo ano a gente foca no que a gente chama de alguns temas estratégicos [...] esse ano, por exemplo, foram elencados quatro, foram recursos humanos, foi o modelo de crescimento da companhia, [...] outro ponto foi a questão de energias renováveis, principalmente biocombustíveis [...]. E por ultimo foi a questão do gás natural ai, em parte pela, pela crise da Bolívia, enfim (E_01).

[...] o problema de uma empresa localizada em um mercado emergente hoje, é realmente o movimento de fundos, movimento de recursos e a atratividade que esse mercado emergente traz aos investidores. Então a Petrobras [...] é obrigada a [...] recorrer ao mercado internacional para financiar as suas atividades (E_03).

[...] a gente tem ali ampla liberdade de opinar, [...] Se é mão de obra própria, pessoal contratado (E_16)

\subsection{Aprendizagem decorrente da análise do ambiente interno}

As afirmações dos entrevistados que compõem a sexta e última categoria de análise demonstram que em sua visão a necessidade de identificar e interpretar as mudanças internas necessárias à adaptação ao ambiente ocasiona uma mudança comportamental decorrente do aprendizado de novos fatos que podem influenciar o desempenho da organização:

[...] percebendo todo esse movimento, toda essa questão do aquecimento global, da questão de mudança climática, da pressão que vai vir em cima dela como está vindo em cima de todas as petroleiras, ela já está migrando para um processo de redirecionamento estratégico [...] (E_02).

a nossa expectativa de futuro que a gente está querendo chegar e com base na experiência, $[\ldots]$ vai acumulando uma capacidade critica que não está também preso aqui dentro [...]. Esse processo de planejar ele é aberto e interativo, uma área critica a outra também (E_05).

[...] esse aprendizado, essa coisa de olhar e aprender, mas também olhar e romper com o que a gente fez no passado é uma dinâmica muito rica (E_09).

Esse planejamento estratégico começou a provocar a gente a pensar assim [...]. Como que vai, como serão as refinarias, plataformas, o que que elas vão estar fazendo, então aquelas fazendas [...] de energia eólica [...]; nós temos que passar pelo metano, [...] como sendo uma fase de transição, você vai deixar os combustíveis pesados para trás, partir para os combustíveis mais leves (E_16).

Destarte, as informações processadas com base na análise de fatos que ocorrem no ambiente externo e no interior da organização sofrem filtros mentais ou mapas cognitivos influenciados pela experiência e formação de cada indivíduo, evidenciam a presença de preceitos das escolas de formulação estratégica cognitiva e de aprendizagem, segundo a qual, na concepção de Mintzberg, Ahlstrand e Lampel (2000), a aprendizagem se inicia pela necessidade determinada por mudanças do meio ambiente e internas, observadas durante a implementação das estratégias no passado. 
O processo de análise do ambiente e sua relação com a aprendizagem organizacional: um estudo de caso

\subsection{Análise dos resultados segundo o modelo conceitual de aprendizagem nas organizações}

Conforme se viu no referencial teórico, os modos de aprendizagem descritos por Pawlowsky (2001) correspondem a três instâncias existenciais da condição humana: o conhecimento, os sentimentos e a ação. Na instância cognitiva, a pesquisa mostrou a presença da racionalidade no processo decisório da empresa, que revelou o reconhecimento dos entrevistados quanto à presença de aprendizagem por meio de mudanças de estruturas cognitivas. A instância dos sentimentos aborda a aprendizagem com base na interpretação do comportamento humano, considerando que a realidade é construída socialmente pelo compartilhamento de significados, especialmente em relação a artefatos, símbolos, metáforas ou mitos. Novamente se pode observar, nos relatos dos gestores, situações em que se reconhece a presença de aprendizagem pela própria evolução da forma pela qual os atuais gestores enxergam os desafios de competitividade e de missão da organização. A aprendizagem pela ação, por sua vez, se revela na pesquisa em depoimentos que lembram estratégias bem ou mal sucedidas que conduziram a organização a refinar a precisão de suas projeções do futuro e a interpretação de desafios ambientais.

Quanto aos tipos de aprendizagem, pretendeu-se identificar a presença, na organização, das de circuito simples, duplo e triplo. Pode-se afirmar que a aprendizagem de circuito simples está presente na própria ação da experiência e da transmissão de informações realizadas por meio de processos formais e regulares. A de circuito duplo também se evidencia, considerando que as experiências e observações de situações de sucesso ou insucesso conduzem a novos modelos mentais dos gestores.

Mais complexa, porém, se revela a análise da presença de aprendizagem em circuito triplo. $\mathrm{O}$ modelo teórico adotado para este estudo assume que esse tipo de aprendizagem ocorre quando os princípios essenciais da organização entram em discussão, provocando questões relacionadas ao que a organização pretende ser, quais contribuições deseja proporcionar, o que ela valoriza e assim por diante. No caso estudado observa-se que o planejamento estratégico ocorre como um meio de obtenção de melhoria de desempenho e busca de antecipação das decisões com base em uma visão de futuro. Essa característica revela um potencial para que a empresa desenvolva novos princípios organizacionais, o que configuraria a presença do circuito triplo de aprendizagem. Contudo, não se pode afirmar, de modo 
conclusivo, se de fato o processo de planejamento no caso estudado conduz a esses novos princípios ou simplesmente à ratificação de princípios existentes, face a seu caráter intencional, estruturado e sistemático.

Quanto aos processos de aprendizagem, nota-se que existe, dentre os gestores da organização pesquisada, uma preocupação com o monitoramento, tanto do ambiente externo quanto do desempenho interno, como forma de acompanhar as tendências e formular estratégias alinhadas com oportunidades e mudanças em geral. Há também um reconhecimento da importância do desdobramento das estratégias em forma de metas visando à facilitação desse monitoramento de resultados. Essa atitude corrobora a opinião de Pawlowsky (2001), que entende que a identificação de informações parece relevante para a aprendizagem, para a criação do conhecimento ou para ambos. Igualmente presentes no discurso dos entrevistados, a troca e a difusão do conhecimento, apontados pelo autor como segundo passo do processo de aprendizagem, são indicadas como aspectos fundamentais para que as estratégias se efetivem, sob pena de se constituírem barreiras à implementação. O terceiro passo, representado pela integração do conhecimento a sistemas de conhecimento já existentes, surge como característica básica do processo de planejamento estratégico descrito nas entrevistas. $\mathrm{O}$ quarto e último passo descrito por Pawlowsky (2001), que representa a transformação do novo conhecimento em ação, aplicando-o às rotinas da organização de forma a impactar o comportamento organizacional, está refletido na própria concepção do processo de implementação de estratégias, que se inicia com a participação do próprio presidente da empresa e se difunde pelas diversas áreas e níveis da estrutura organizacional.

Por fim, pode-se destacar que a aprendizagem, no processo de análise e interpretação do ambiente ocorre por meios formais, tais como: cursos, treinamentos e palestras destinadas à divulgação das tendências futuras. Não obstante, há também situações de aprendizagem informal, promovidas pela constante revisão de práticas e comportamentos para adequá-los a novas condições. $\mathrm{O}$ desdobramento de cenários alternativos considerados para o estabelecimento de estratégias e a discussão de caminhos alternativos para o futuro dos negócios e a adaptação a um contexto de mudança, constituem mecanismos de aprendizagem informal e incidental.

\section{CONSIDERAÇÕES FINAIS}

REAd I Porto Alegre - Edição 73 - Nº 3 - set/dez 2012 - p. $779-812$ 
O processo de análise do ambiente e sua relação com a aprendizagem organizacional: um estudo de caso

A reflexão sobre as principais descobertas para cada uma das dimensões observadas no presente estudo possibilita, inicialmente, identificar que a organização realiza um processo contínuo e estruturado de análise e interpretação de tendências do meio ambiente. Esse processo fundamenta o plano estratégico anual, discutido e revisto semanalmente por um grupo de gestores que representam todas as áreas internas da empresa.

Existe uma área corporativa, responsável pela gestão do processo de formulação e implementação de estratégias, denominada Estratégia e Desempenho Empresarial (E.D.E.), que assessora todas as demais áreas, fornecendo-lhes subsídios de informação sobre o desempenho passado e as tendências futuras. Nessa área, são elaborados relatórios semanais com notícias dos setores em que a empresa atua, que são enviados semanalmente às gerências de todas as áreas de negócios, assim proporcionando uma constante atualização dos gestores quanto a tendências do ambiente.

As estratégias da empresa se originam em um Comitê de Negócios, com base em uma prospecção de tendências ambientais que são analisadas e discutidas pelos participantes desse órgão, levando-os a estabelecer três cenários alternativos como referência para a formulação de estratégias corporativas da empresa.

Como primeira conclusão, é possível considerar que aspectos como a preocupação com a identificação de tendências, sua interpretação e a construção de cenários representam um processo de mudança cognitiva. Tal conclusão decorre de que esses aspectos requerem do participante o desenvolvimento de uma visão voltada para o futuro e receptiva a mudanças em relação ao que se praticou no passado. Pode-se concluir, também, que esse fato, associado à necessidade de formular estratégias que beneficiem a empresa de forma integrada e considerando as especificidades das diversas áreas, proporciona aprendizagem como fruto do compartilhamento do conhecimento entre indivíduos de diversas áreas.

A partir da concepção do Comitê de Negócios sobre o futuro desejado, acionam-se canais hierarquicamente superiores para a aprovação e deliberação das estratégias a serem adotadas. Assim, ocorre a formalização das estratégias a implementar. Isso não significa, contudo, que as estratégias foram impostas às diversas áreas. Ao contrário, a maioria dessas estratégias são propostas pelos representantes de áreas no Comitê de Negócios a partir de projetos propostos por seus integrantes, o que denota o espaço para a emergência de estratégias, posteriormente deliberadas. 
Outro espaço para as estratégias emergentes surge da velocidade de mudança das variáveis ambientais, devido às quais ocorrem situações em que a implementação não é possível, levando à necessidade de adaptação da estratégia às novas condições.

Outra possível conclusão seria a de que quando as estratégias são implementadas ocorre um monitoramento de resultados, não só no âmbito interno da organização como também em termos da influência sobre o comportamento do mercado, de forma a proporcionar um novo estágio de conhecimento para os gestores e assim caracterizando aprendizagem em circuito duplo. Como esse novo estágio de conhecimento irá influenciar as atitudes dos gestores em processos de formulação de novas estratégias para o futuro em busca de melhoria de desempenho e aperfeiçoamento das ações, compreensão e conhecimento, existem condições favoráveis à aprendizagem em circuito triplo. Mesmo assim, entende-se que persiste uma dúvida se o processo de planejamento observado conduz, efetivamente, a organização a absorver e adotar novos princípios ou simplesmente se ratificam os princípios existentes, dado que ele se realiza de forma intencional, estruturada e sistemática. Apesar dessa limitação a inferências sobre a efetiva presença de aprendizagem em circuito triplo, é possível notar que ela se realiza, no mínimo, em circuitos simples e duplo.

Essas observações, se interpretadas a partir do modelo de estudo para a gestão da aprendizagem organizacional proposto por Pawlowski (2001), conduzem à conclusão de que a análise do ambiente externo efetuada no processo de planejamento estratégico na organização pesquisada proporciona aprendizagem, tanto em nível individual como em nível organizacional.

Cabe ressaltar que por mais cuidado e dedicação que se tenha ao elaborar uma pesquisa, é comum que ela possua limitações. Neste estudo, de natureza exploratória e descritiva, o objetivo não é conclusivo e as descobertas não podem ser consideradas como aplicáveis a quaisquer situações. Assim sendo, o propósito do estudo é limitado a levantar novas abordagens e perspectivas sobre o tema aplicadas a uma situação específica. Além disso, a opção por entrevistar um grupo de gestores representa uma limitação do presente estudo, ainda que conscientemente assumida. As próprias limitações do estudo indicam outros aspectos que podem ser objetos de maior exploração. Um deles seria a diferença de percepção do fenômeno entre os profissionais de diversos níveis hierárquicos na organização, o que não foi explorado por não ser o foco do presente trabalho. Apesar das limitações apontadas acredita-se que a presente pesquisa revela-se uma contribuição relevante na medida em que: (a) trata de um tema pouco explorado entre os pesquisadores brasileiros que estudam o 
O processo de análise do ambiente e sua relação com a aprendizagem organizacional: um estudo de caso

fenômeno da aprendizagem nas organizações; (b) pontua elementos importantes da articulação entre o planejamento estratégico e a aprendizagem na empresa estudada; (c) amplia o nosso olhar para as questões da aprendizagem ao tomar como uma das referências teóricas fundamentais o modelo conceitual de Pawlowisky (2001) que se mostrou bastante promissor ao exame de problemáticas desta natureza; (d) confirma a tendência encontrada na literatura internacional por Bapuj e Crossan (2004) de que a postura estratégica de uma organização influencia a aprendizagem organizacional ao prover um contexto que auxilia na percepção e interpretação do ambiente. A partir dessas constatações sugere-se que novas pesquisas com este foco sejam efetuadas privilegiando-se outros segmentos empresariais e empresas que não possuem um processo de planejamento estratégico tão amadurecido quanto o da organização pesquisada.

\section{REFERÊNCIAS}

ACKOFF, R. L. Planejamento empresarial. Rio de Janeiro: Livros Técnicos e Científicos, 1976..

ALVES -MAZZOTTI, A. J. O método nas ciências sociais. In: ALVES -MAZZOTTI, A. J.; GEWANDSZNAJDER, F. O método nas ciências naturais e sociais: pesquisa quantitativa e qualitativa. São Paulo: Pioneira Thomson Learning, 2002. p. 109-187.

ANDREWS, K.R. The concept of corporate strategy. Homewood, IL; Irwin, 1971..

ANSOFF, H. I. Estratégia empresarial. São Paulo: McGraw-Hill do Brasil, 1977.

ANTONELLO, C. S.; GODOY, A. S. Uma agenda brasileira para os estudos em aprendizagem organizacional. Revista de Administração de Empresas, v. 49, n.3, p. 266 281, 2009.

. A encruzilhada da aprendizagem organizacional: uma visão multiparadigmática.

Revista de Administração Contemporânea, v. 14, n. 2, p. 310-332, 2010. 
ARGYRIS, C. Good communications that blocks learning. Harvard Business Review, v. 72, n. 4, p. 77-85, Jul./Aug. 1994.

ARGYRIS, C.; SCHÖN, D. A. Organizational learning: a theory of action perspective. Reading/Mass: Addison-Wesley, 1978.

ARGYRIS, C.; SCHÖN, D. A. Organizational learning II: theory, method, and practice. New York: Addison-Wesley, 1996.

BAPUJI, H.; CROSSAN, M. From questions to answers: reviewing organizational learning research. Management Learning, v. 35, n. 4, p. 397-417, 2004.

BEER, M.; EISENSTAT, R. A. The silent killers of strategy implementation and learning. Sloan Management Review, v. 41, n. 4, p. 29- 40, 2000.

BIERLY, P; CHAKRABARTI, A. Generic knowledge strategies in the US pharmaceutical industry. Strategic Management Journal, v. 17, n. 1/2 , p. 123-135, 1996.

CERTO, S. C.; PETER, J. P.; MARCONDES, R. C.; CESAR, A. M. R. Administração estratégica: planejamento e implantação da estratégia. $2^{\mathrm{a}}$. ed., São Paulo: Pearson Education do Brasil, 2005.

CHAKRAVARTHY, B. S.; WHITE, R. Strategy process: forming, implementing and changing strategies. In: PETTIGREW, A.; THOMAS, H.; WHITTINGTON, R.. Handbook of strategy and management. London: SAGE Publications, 2002. p. 183-205.

CROSSAN, M. M.; LANE, H. W.; WHITE, R. E. An organizational learning framework: from intuition to institution. The Academy of Management Review, v. 24, n. 3, p. 522-537, Jul. 1999.

CROSSAN, M. M.; BERDROW, I. Organizational learning and Strategic Renewal. Strategic Management Journal, v. 24, n. 11, p.1087-1105, Nov.2003.

CYERT, R. M.; MARCH, J. G. A behavorial theory of the firm. Englewood Cliffs, N.J.: Prentice Hall, 1963. 
O processo de análise do ambiente e sua relação com a aprendizagem organizacional: um estudo de caso

DEFILLIPPI, R.; ORNSTEIN, S. Psychological perspectives underlying theories of organizational learning. In: EASTERBY-SMITH, M.; LYLES, M. A. The Blackwell handbook of organizational learning and knowledge management. Oxford: Blackwell Publishing, 2003, p. 19-37.

DIERKES, M.; BERTHOIN ANTAL, A.; CHILD, J.; NONAKA, I. Organizational learning and knowledge, New York: Oxford, 2001.

DODGSON, M. Organizational learning: a review of some literatures. Organizations Studies, v. 14, n. 3, p. 375-394, 1993.

EASTERBY-SMITH, M. Disciplines of organizational learning: contributions and critiques. Human Relations, v. 50, n. 9, p. 1085-1113, Sept. 1997.

EASTERBY-SMITH, M.; ARAUJO, L. Organizational learning: current debates and opportunities. In: EASTERBY-SMITH, M.; BURGOYNE, J.; ARAUJO, L. (editores). Organizational learning and the learning organization: developments in theory and practice. London: SAGE, 2000.

EASTERBY-SMITH, M.; LYLES, M. A. The Blackwell handbook of organizational learning and knowledge management. Oxford: Blackwell Publishing, 2003.

EASTERBY-SMITH, M.; SNELL, R.; GHERARDI, S. Organizational learning: diverging communities of practice? Management Learning, v. 29, n. 3, p. 259-272, Sept. 1998.

EISENHARDT, K. Building theories from case study research. Academy of Management Review, v.14, n.4, p. 532-550, 1989.

ENDLICH, N. A. An Investigation of the Nexus Between Strategic Planning and Organizational Learning. Dissertation submitted to the Faculty of the Virginia Polytechnic Institute and State University in partial fulfillment of the requirements for the degree of Doctor of Philosophy in Human Development. October, 2001, Falls Church, Virginia. Disponível em http://scholar.lib.vt.edu/theses/available/etd-12082001-151605/ unrestricted/ Chapters.pdf. Acesso em 04/11/2006.

EXAME. Edição Especial Melhores e maiores, São Paulo: Editora Abril. Edição 995E , jul. 2011. 
Adilson Caldeira \& Arilda Schmidt Godoy

FIOL, C. M.; LYLES, M.A. Organizational Learning. Academy of Management Review, v. 10, n.4, p. 803-813, 1985.

GHEMAWAT, P. A estratégia e o cenário dos negócios: textos e casos. Porto Alegre: Bookman, 2000.

GLUCK, F.; KAUFMAN, S. P.; WALLECK, A. S. Strategic Management for Competitive Advantage. Harvard Business Review, v. 58, n. 4, p. 154-161,1980.

GODOY, A. S.; ANTONELLO, C.S. Cartografia da aprendizagem organizacional no Brasil. Uma revisão multiparadigmática. In: ANTONELLO, C. S.; GODOY, A. S. (Ed.). Aprendizagem organizacional no Brasil. Porto Alegre: Bookman, 2011. p. 51-77.

GUZZO, R.A.; SHEA, G.P. Group Effectiveness: What Really Matters?; What Matters? Why It Matters What to Do A Case in Point Implications References. Sloan Management Review. v. 28, n. 3, p. 25-31, spring 1987.

HARTLEY, J. F. Case studies in organizational research. In: CASSELL, C.; SYMON, G. (ed.) Qualitative methods in organizational research: a practical guide. London: Sage, 1994. p.323-333.

HEDBERG, B.; WOLFF, R. Organizing, learning, and strategizing: from construction to discovery. In: DIERKES, M.; BERTHOIN ANTAL, A.; CHILD, J.; NONAKA, I. Handbook of organizational learning and knowledge, New York:Oxford, 2001, p.535-556.

HODGKINSON, M. A shared strategic vision: dream or reality? The Learning Organization, v. 9, n. 2, p. 89- $95,2002$.

HOLLENBECK, J. R.; ILGEN, D. R.; SEGO, D.J.; HEDLUND, J.; MAJOR, D. A.; PHILLIPS, J. Extending the multilevel theory of team decision making: Effects of feedback and experience in hierarchical teams. Academy of Management Journal, v. 41, n. 3, p. 269282, jun. 1998. 
O processo de análise do ambiente e sua relação com a aprendizagem organizacional: um estudo de caso

HUBER, G. P. Organizational learning: the contributing processes and the literature.

Organizational Science, v. 2, n.1, p. 88-115, 1991.

JOHNSON, J. M. In-depth interviewing. In: HOLSTEIN, J. A.; GUBRIUM, J. F. (Eds.) Handbook of interview research: context \& method. Thousand Oaks: Sage Publications, 2002. p. 103-119.

KIM, D. H. The link between individual and organizational learning. Sloan Management Review, Cambridge, v. 35, n.1, p. 37-50, fall 1993.

KIM, L. Crisis construction and organizational learning: capability building in catching-up at Hyundai Motor. Organization Science, v. 9, n. 4, p. 506-521, 1998.

KING, N. Template analysis. In: SYMON, G.; CASSELL, C. (Ed.) Qualitative methods and analysis in organizational research: a practical guide, Thousand Oaks, CA: Sage, 1998. p. 118-134.

LORANGE, P; VANCIL, R. F.; How to design a strategic planning system. Harvard Business Review, v. 54, n. 5, p. 75-81, 1976.

LEVITT, B.; MARCH, J. Organizational Learning. Annual Review of Sociology, v. 14, p. 319340, 1988.

MAIER, G. PRANGE, C.; ROSENSTIEL, L. V. Psychological perspectives of organizational learning. In: DIERKES, M.; BERTHOIN ANTAL, A.; CHILD, J. e NONAKA, I. Handbook of organizational learning and knowledge, New York: Oxford, 2001. p. 14-34.

MERRIAM, S. B. Qualitative research and case study. Applications in education. San Francisco, CA: Jossey-Bass, 1998.

MINTZBERG, H. Strategy-making in three modes, California Management Review, v.. 16, n.2, p. 44-53, winter, 1973. 
MINTZBERG, H.; AHLSTRAND, B.; LAMPEL, J. Safári de estratégia: um roteiro pela selva do planejamento estratégico. Porto Alegre: Bookman, 2000.

MINTZBERG, H.; QUINN, J. B. O processo da estratégia. 3.ed. Porto Alegre: Bookman, 2001.

MUMFORD, A. A learning approach to strategy. Journal of Workplace Learning, v. 12, n. 7, p. 265- 2712000.

PAWLOWSKY, P. The treatment of organizational learning in management science. In: DIERKES, M.; BERTHOIN ANTAL, A.; CHILD, J. e NONAKA, I. Handbook of organizational learning and knowledge, New York: Oxford, 2001. p. 61-88.

PETROBRAS Petróleo Brasileiro S.A. Apresenta informações institucionais da empresa. Disponível em: <http://www.petrobras.com.br>, Acesso em: 11 jul. 2006 às 17h33m.

PLANO DE NEGÓCIOS PETROBRAS 2015, 2007. <http://www.petrobras.com.br>, Acesso em: 17 dez. 2007 às $21 \mathrm{~h} 12 \mathrm{~m}$.

PLANO DE NEGÓCIOS PETROBRAS 2020, 2011. <http://www.petrobras.com.br/pt/quemsomos/estrategia-corporativa/downloads/pdf/plano-negocios.pdf>, Acesso em: 1 out. 2011 às $12 \mathrm{~h} 04 \mathrm{~m}$.

PLANO ESTRATÉGICO PETROBRAS 2020, 2007. <http://www.petrobras.com.br>, Acesso em: 17 dez. 2007 às $23 \mathrm{~h} 26 \mathrm{~m}$.

POPPER, M.; LIPSHITZ, R. Organizational learning: mechanisms, culture, and feasibility. Management Learning, v. 31, n. 2, p. 181-196, 2000.

PORTER, M. E. Estratégia competitiva: técnicas para análise de indústria e da concorrência. 7a ed., Rio de Janeiro: Editora Campus, 1986.

ROSENKOPF, L.; NERKAR, A. Beyond local search: boundary-spanning, exploration, and impact in the optical disk industry. Strategic Management Journal, v. 22, n. 4, p. 287-306, 2001 
O processo de análise do ambiente e sua relação com a aprendizagem organizacional: um estudo de caso

RUAS, R.; ANTONELLO, C. S.. Repensando os referenciais analíticos em aprendizagem organizacional: uma alternativa para análise multidimensional. Revista de Administração Contemporânea, v. 7, n. 3, p. 203-212, 2003.

SCHAFFER, U.; WILLAUER, B. Strategic planning as a learning process. Schmalenbach Business Review, v. 55, n. 2, p. 86- 107,2003.

SENGE, P. M. A Quinta Disciplina - arte, teoria e prática da organização de aprendizagem. São Paulo, Best Seller, 1990.

SPENDER, J. W. Firms knowledge-sharing strategies in the global innovation system: empirical evidence from the flat panel display industry. Strategic Management Journal, v. 24, n. 3, p. 217-233, 2003.

THOMAS, J. B; SUSSMAN, S. W.; HENDERSON, J. C. Understanding "strategic learning": Linking organizational learning, knowledge management and sensemaking. Organization Science, v. 12, n. 3, p. 331- 345, 2001.

TSANG, E. W. K. Organizational Learning and the Learning Organization: A Dichotomy Between Descriptive and Prescriptive research. Human Relations, v. 50, n. 10, p. 73-89, 1997.

VISSER, M. Deutero-learning in organizations: a review and a reformulation. The Academy of Management Review, v. 32, n. 2, p. 659-667, 2007. 